\title{
The Relationship between Meal Regularity and Oral Health and Metabolic Syndrome of Adults in Single Korean Households
}

\author{
Jin-Ah Jung ${ }^{1}$, Hye-Won Cheon ${ }^{2,}$, and On-Ju Ju ${ }^{3}$ \\ 'Department of Dental Hygiene, Gwangyang Health Sciences University, Gwangyang 57764, ${ }^{2}$ Department of \\ Dental Hygiene, Howon University, Gunsan 54058, ${ }^{3}$ Department of Dental Hygiene, Wonkwang Health Sciences \\ University, Iksan 54538, Korea
}

\begin{abstract}
Background: This study aimed at investigating the meal regularity, health, and oral health habits of single Korean households to understand the impact of these factors on the risk of metabolic syndrome, in addition to preventing and managing metabolic syndrome.

Methods: Using raw data from the 8th Korea National Health and Nutrition Examination Survey (2019), 274 study subjects, aged 19 to 64 , were selected primarily from single adult households. Complex sample statistical analysis was performed using the Predictive Analytics Software Statistics ver. 18.0 program.

Results: Regarding the meal regularity in single-person households in Korea, the younger group outperformed the middle-aged group, and those who drank more than once a month performed better than those who drank less than once a month. In terms of oral health, regardless of the age and the income level, participants who ate three meals a day had a higher rate of speech problems and chewing difficulties than those who ate irregularly or regularly on a regular day. Factors influencing the risk of developing metabolic syndrome were age, speech problems, and frequency of toothbrushing. Compared to the younger group, there were 0.361 times more people in the middle-aged group; and compared to those without speech problems, there were 1. 161 more people with speech problem. Compared to those who tooth brushed more than four times a day, there were 1.284 more people who tooth brushed 2 to 3 times a day and there were 5.673 times more people who tooth brushed less than once. Conclusion: Based on the study results, it is necessary to implement a program that can plan and apply customized management measures and prevent metabolic syndrome by improving and correcting the health and oral health behaviors of single-person households in Korea. Therefore, active mediation measures, such as support and publicity at the local or national level, should be planned.
\end{abstract}

Key Words: Meal regularity, Metabolic syndrome, Oral health, Single-person households

\section{Introduction}

Due to rapid socioeconomic development and the improvement of national income levels, lifestyle, and dietary culture has changed dramatically in response to the pursuit of convenience in life. The number of single-person households is increasing to the point where new terms such as "solo economy" have been coined". As of 2019,
6.148 million single-person households accounted for $30.2 \%$ of all households, with 20 's accounting for $18.2 \%$ of all single-person households ${ }^{2}$. The increase in singleperson households is also driving up the consumption and delivery of instant and fast foods ${ }^{3)}$ in addition to a high intake of calories, fat, and sodium, which can lead to obesity, high blood pressure, diabetes, stroke, and cancer ${ }^{1)}$.

Among chronic diseases, metabolic syndrome is a 
disease that is diagnosed with three or more cases of abdominal obesity, cholesterol, triglycerides, diabetes, and high blood pressure ${ }^{4)}$, which triples the risk of developing heart disease and increases the risk of diabetes by six times ${ }^{5)}$. Therefore, metabolic syndrome has been reported to be closely related to dietary habits and balanced nutrition ${ }^{6}$. Previous studies on dietary and metabolic syndrome have revealed an association between dietary patterns and metabolic syndrome and are recommended for the prevention and management of metabolic syndrome when consuming hybrid grain and healthy foods with added vegetables and fruit ${ }^{7}$. Moreover metabolic syndrome has been reported to be lower in people who eat regularly and eat out less frequently than those who usually overeat and dine out ${ }^{8}$. Studies on the dietary habits of singleperson households and the prevalence of metabolic syndrome indicate that eating regularly after menopause reduces the risk of metabolic syndrome in both men and women".

As concern regarding a healthy quality of life increases, oral health is becoming closely related to overall health-related quality of life as well as general health ${ }^{10}$. Therefore, oral health is an important indicator in health care, and it is an essential element of health because it is highly related to general health in nutrition intake and digestion ${ }^{11)}$. The results of a previous study on the risk factors for oral health and metabolic syndrome show that the risk of metabolic syndrome impacting the waist circumference, triglyceride, and blood pressure was higher in those who did use a dental clinic and performed less frequent brushing ${ }^{12}$.

A study on the relationship between metabolic syndrome and periodontitis revealed a high community periodontal index prevalence in patients with metabolic syndrome ${ }^{13)}$, moreover, inflammation and metabolic markers tend to increase the number of periodontal pockets ${ }^{14)}$. This suggests that metabolic syndrome and periodontal disease are related. Factors affecting periodontal disease were discomfort in chewing, throbbing or pain, and bleeding gums $^{15)}$, and the greatest risk of periodontal disease was chewing difficulty ${ }^{16)}$. In addition, periodontal disease was found to be high in patients with poor oral conditions, chewing difficulty, and speech problems ${ }^{17)}$. Therefore, it is thought that chewing difficulty and speech problems are also related to metabolic syndrome.

According to the findings of a study on the prevalence of metabolic syndrome based on oral health behavior, the prevalence of metabolic syndrome was highest among those who brushed their teeth less than once and when regular dental examinations were not conducted ${ }^{18)}$. A study of patients with metabolic syndrome on the relevance of oral health knowledge, attitudes, and behaviors to the oral health impact index, the quality of life related to oral health is poor if they say they have had a dental experience in the past year ${ }^{19)}$. As a result of reviewing these literatures, oral health behavior is thought to be related to the occurrence of metabolic syndrome, including eating habits and lifestyle, and studies on the relationship between dietary rules and oral health and metabolic syndrome in adults in single-person households are lacking.

Therefore, this study was conducted to understand the dietary rules, in addition to the health and oral health behaviors of single-person households and to examine their relationship with metabolic syndrome risk factors. By improving health and oral health of single-person households, this study presents the basic data for the prevention and management of metabolic syndrome.

\section{Materials and Methods}

\section{Study subjects}

This study used raw data ${ }^{20)}$ from the 8th Korea National Health and Nutrition Examination Survey (KNHANES) conducted in 2019.

The study subjects were 433 adults aged 19 to 64 who responded to the survey, 32 people diagnosed with cancer, 1 patient who had been sick for 15 days or more, and 126 people with missing values. A total of 274 people who answered all the questions were selected as the final subjects, and the model for selecting he study subjects is presented in Fig. 1.

\section{Study method}

In this study, the variables of the health survey, nutrition survey, and oral examination data of the 8th KNHANES (2019) were converted and used. Metabolic syndrome was 


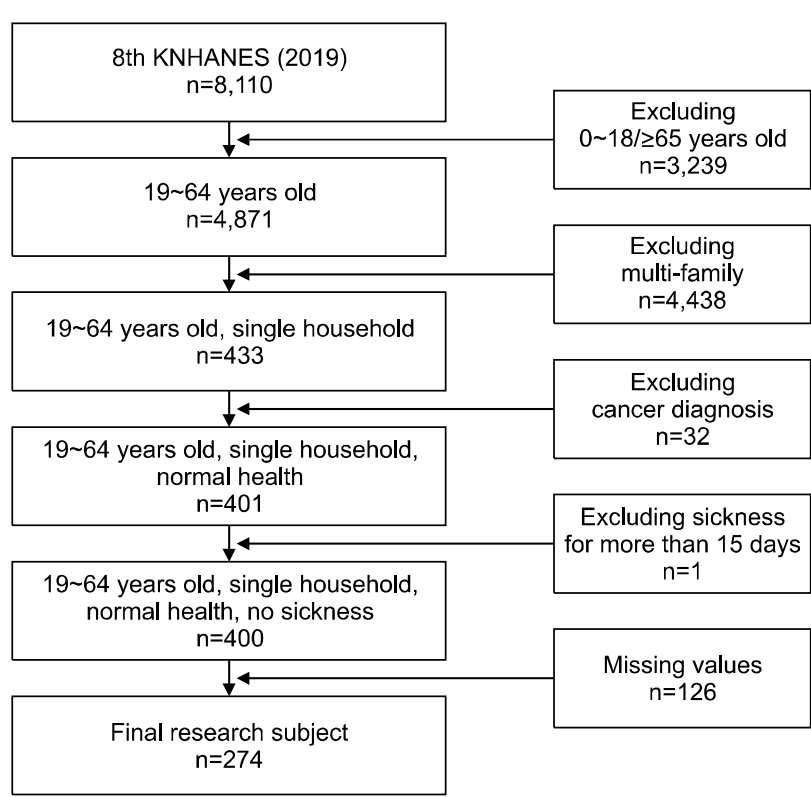

Fig. 1. Research subject selection model. KNHANES: Korea National Health and Nutrition Examination Survey.

the dependent variable, and the independent variables were general characteristics, dietary rules, and oral health.

\section{1) Diagnosis of metabolic syndrome}

The data of this study were based on the 8th period (2019) of the KNHANES. The diagnosis of metabolic syndrome was defined according to the NCEP-ATP (National Cholesterol Education Program-Adult Treatment Panel) III diagnostic criteria and the Korea Obesity Society criteria. Metabolic syndrome is defined as metabolic syndrome when three or more of the following five factors are present: abdominal obesity (above $90 \mathrm{~cm}$ waist circumference for men, over $85 \mathrm{~cm}$ for women), hypertriglyceridemia (over $150 \mathrm{mg} / \mathrm{dl}$ for blood), HDLcholesterol (under $40 \mathrm{mg} / \mathrm{dl}$ for men, $<50 \mathrm{mg} / \mathrm{dl}$ for women), hypertension (over $140 \mathrm{mmHg}$ for contractor blood pressure, or over $90 \mathrm{mmHg}$ for relaxation blood pressure), impaired fasting glucose (fasting glucose 100 $\mathrm{mg} / \mathrm{dl}$ or more, people who took insulin injections and diabetes drugs for diabetes blood glucose care $)^{4,20)}$.

\section{2) General characteristics}

The general characteristics were sex, age, education level, income level, smoking status, and drinking status. Sex was divided into male and female, and the age groups were categorized as young people (19 39) and middleaged people $(40 \sim 64)$. The education level was categorized as below high school and above college and the income level was divided into low, middle-low, middle-high, high for one-generation households and single-person households. In the category for smoking status those who smoked less than 5 packs (100 cigarettes) and more than 5 packs (more than 100 cigarettes) in their lifetime were classified as smokers and those who had never smoked were classified as non-smokers. Alcohol consumption was classified as those who consumed alcohol less than once a month and those who consumed alcohol more than once a month over a span of one year.

\section{3) Meal regularity}

The weekly meal information $(0 \sim 7$ breakfast, lunch, and dinner frequency according to the weekly unit) was collected and divided into irregular or regular meals, regular groups of two meals, and regular groups of three meals.

\section{4) Oral health}

Oral health variables used in this study were perceived oral health, speech problems, chewing difficulty, toothache experience, frequency of toothbrushing per day, and oral examinations for one year. Perceived oral health categories like "very good," "good," "moderate," "poor, and "very poor" were reclassified into three levels: "good," "moderate," and "poor." Speech problem and chewing difficulty categories like "very uncomfortable," "discomfort," "neutral," "not uncomfortable," and "not at all uncomfortable" were reclassified as: "yes," "neutral," and "no." The experience of toothache in the past year was divided into "yes" and "no." Frequency of toothbrushing per day was reclassified into "less than once," " $2 \sim 3$ times," and "more than 4 times."

\section{Data analysis}

Using the raw data of the 8th KNHANES (2019) used in this study, a planned file was generated considering the distributed estimation layer, survey, health survey, and the weight of the nutrition survey to ensure that the data results were representative and subsequently a complex 
sample analysis was performed. A complex sample chisquare test was performed to investigate the differences in (1) meal regularity and oral health according to general characteristics; (2) metabolic syndrome according to general characteristics; and (3) meal regularity and metabolic syndrome according to oral health. Complex sample logistic regression analysis was performed to determine whether it affected the metabolic syndrome. The collected data were subjected to complex sample statistical analyses using Predictive Analytics Software (PASW) Statistics ver. 18.0 (IBM Corp., Armonk, NY, USA), and the statistical significance level was $\mathrm{p}<0.05$.

\section{Results}

\section{Meal regularity according to the general characteristics of single-person households}

The results of analyzing the differences in meal regularity according to the general characteristics of single-person households are presented in Table 1. There was a statistically significant difference in the meal regularity according to age and alcohol intake. In the middle-aged group, 9.7\% made up the irregular or regular one-meal group, and $25.0 \%$ made up the irregular or regular one-meal group in the youth group, displaying a higher difference than the middle-aged group, which was statistically significant $(\mathrm{F}=11.053, \mathrm{p}<0.001)$. Subjects who drank less than once a month made up $17.8 \%$ of the irregular or regular one-meal group, while those who drank more than once a month made up $23.4 \%$ of the irregular or regular one meal group, which was statistically significant $(\mathrm{F}=3.601, \mathrm{p}=0.031)$.

\section{Oral health according to general characteristics of single-person households and meal regularity}

Table 2 shows the differences in oral health according to the general characteristics and meal regularity of singleperson households. The analysis revealed a statistically significant difference in perceived oral health according to sex. In terms of sex, the perceived oral health for female was divided as 14.3\% (good), 34.7\% (moderate), and $51.0 \%$ (poor); and the perceived oral health for male was $8.3 \%$ (good), $54.1 \%$ (moderate), and $37.7 \%$ (poor), which was statistically significant $(\mathrm{F}=3.489, \mathrm{p}=0.024)$. There was a statistically significant difference between speech problems and chewing difficulty according to age. Speech problems $(\mathrm{F}=11.379, \mathrm{p}=0.005)$ and chewing difficulty $(\mathrm{F}=26.108, \mathrm{p}<0.001)$ made up $0.6 \%$ and $5.9 \%$ in the young group and in the middle-aged group, they made up

Table 1. Meal Regularity according to General Characteristics

\begin{tabular}{|c|c|c|c|c|c|c|}
\hline \multirow[b]{2}{*}{ Variable } & \multirow[b]{2}{*}{ Division } & \multirow[b]{2}{*}{ Total } & \multicolumn{4}{|c|}{ Meal regularity } \\
\hline & & & $\begin{array}{l}\leq \text { One time } \\
\text { regularity }\end{array}$ & $\begin{array}{l}\text { Two times } \\
\text { regularity }\end{array}$ & $\begin{array}{c}\text { Three times } \\
\text { regularity }\end{array}$ & $\mathrm{t}$ or $\mathrm{F}(\mathrm{p})$ \\
\hline \multirow[t]{2}{*}{ Sex } & Male & $154(62.2)$ & $26(18.2)$ & $87(58.3)$ & $41(23.4)$ & $0.151(0.854)$ \\
\hline & Female & $120(37.8)$ & $23(18.4)$ & $57(55.0)$ & $40(26.6)$ & \\
\hline \multirow[t]{2}{*}{ Age } & Young adult & $128(55.9)$ & $32(25.0)$ & $77(61.1)$ & $19(13.9)$ & $11.053(<0.001)$ \\
\hline & Middle-aged & $146(44.1)$ & $17(9.7)$ & $67(52.1)$ & $62(38.2)$ & \\
\hline \multirow[t]{2}{*}{ Education } & $\leq$ High school & $161(52.1)$ & $28(17.4)$ & $75(53.4)$ & $58(29.1)$ & $1.178(0.307)$ \\
\hline & $\geq$ College & $113(47.9)$ & $21(19.2)$ & $69(61.1)$ & $23(19.7)$ & \\
\hline \multirow[t]{4}{*}{ Income } & Low & $91(29.5)$ & $18(18.2)$ & $42(51.9)$ & $31(29.9)$ & $1.397(0.228)$ \\
\hline & Middle-low & $72(25.3)$ & $14(21.2)$ & $29(47.1)$ & $29(31.6)$ & \\
\hline & Middle-high & $55(22.2)$ & $12(23.1)$ & $35(65.2)$ & $8(11.7)$ & \\
\hline & High & $56(23.0)$ & $5(10.6)$ & $38(66.9)$ & $13(22.5)$ & \\
\hline \multirow[t]{2}{*}{ Smoking } & Non-smoker & $119(38.3)$ & $21(17.3)$ & $58(55.7)$ & $40(27.0)$ & $0.251(0.776)$ \\
\hline & Current smoker & $155(61.7)$ & $28(18.9)$ & $86(58.0)$ & $41(23.1)$ & \\
\hline \multirow[t]{2}{*}{ Alcohol intake } & $<1$ time/month & $32(9.4)$ & $42(17.8)$ & $134(59.5)$ & $66(22.7)$ & $3.601(0.031)$ \\
\hline & $\geq 1$ time/month & $242(90.6)$ & $7(23.4)$ & $10(33.8)$ & $15(42.8)$ & \\
\hline
\end{tabular}

Values are presented as unweighted count (weighted \%).

F: Rao-Scott test. 


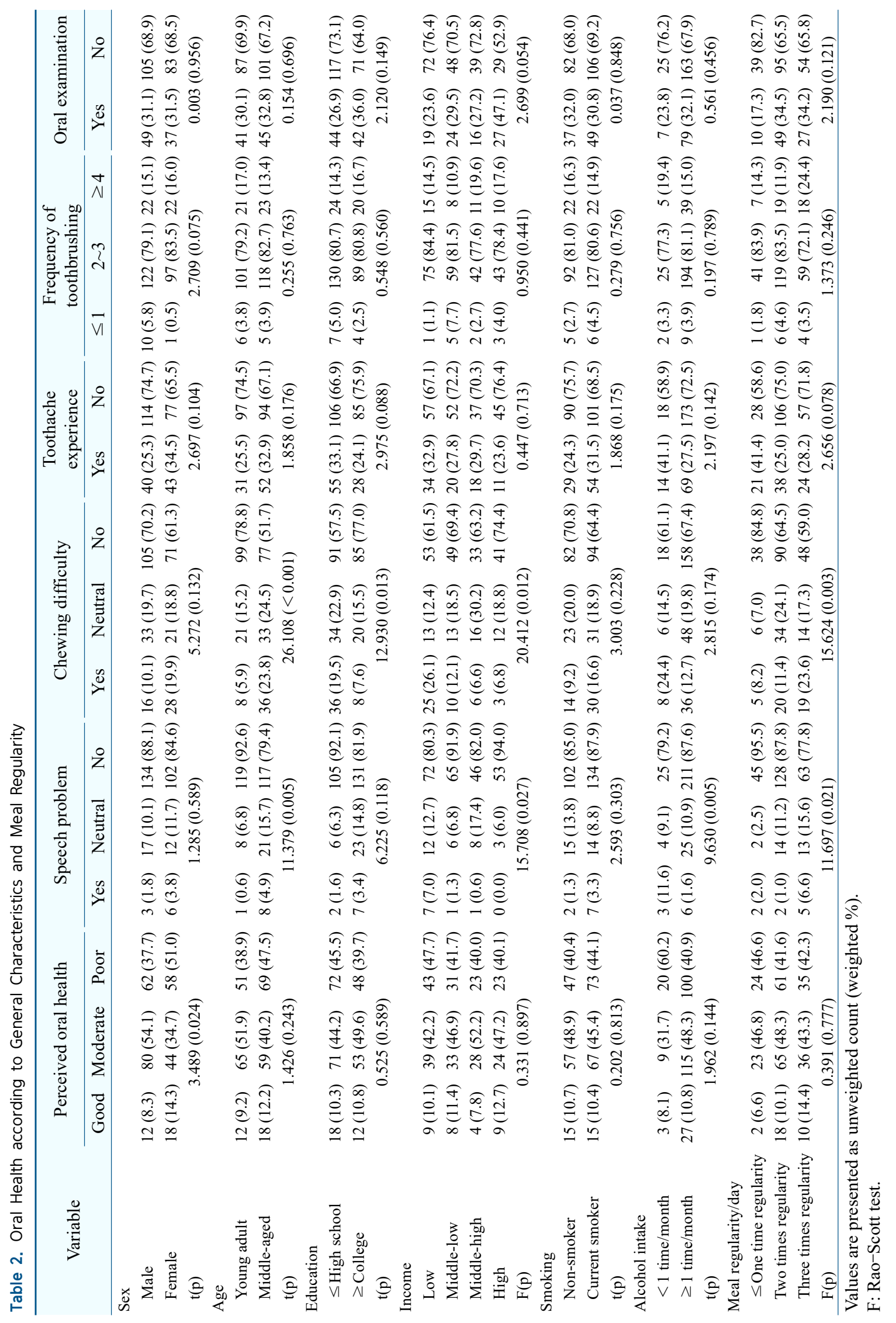


$4.9 \%$ and $23.8 \%$ respectively, which was higher than the younger age group, and statistical significance was noted.

There was a statistically significant difference in chewing difficulty according to education level. The chewing difficulty was $7.6 \%$ for college graduates or higher, $19.5 \%$ for high school graduates or lower, which was higher than that of college graduates or higher and was statistically significant $(\mathrm{F}=12.930, \mathrm{p}=0.013)$. There is a statistically significant difference between speech problems and chewing difficulty according to income level. The lower the income, the higher the speech problem $(\mathrm{F}=15.708, \mathrm{p}=0.027)$ and chewing difficulty $(\mathrm{F}=20.142$, $\mathrm{p}=0.012$ ), which was statistically significant. There was a statistically significant difference in speech problems according to alcohol intake. Subjects who drank more than once a month and had speech problems made up $1.6 \%$, and those who drank less than once a month and had speech problem made up $11.6 \%$, which was higher than those who drank more than once a month, which was statistically significant $(\mathrm{F}=9.630, \mathrm{p}=0.005)$. There was a statistically significant difference between speech problems and chewing difficulty according to the meal regularity. In the three times regularity group, speech problems $(F=11.697$, $\mathrm{p}=0.021)$ and chewing difficulty $(\mathrm{F}=15.624, \mathrm{p}=0.003)$ were higher at $6.6 \%$ and $23.6 \%$, respectively, than in the group who ate less than twice the regularity and was statistically significant.

\section{Metabolic syndrome according to general characteristics of single-person households and meal regularity}

Table 3 shows the differences in metabolic syndrome according to the general characteristics of single-person households and meal regularity. There was a statistically significant difference in metabolic syndrome according to age. In the youth group, the metabolic syndrome was abnormal in $12.4 \%$ of the study subjects, and in the middle-aged group, it was $28.2 \%$, which was higher than that of the younger age group and was statistically significant $(\mathrm{F}=6.652, \mathrm{p}=0.012)$.

\section{Metabolic syndrome according to oral health of single-person households}

Table 4 shows the results of analyzing the differences in metabolic syndrome according to the oral health of single-person households. There was a statistically

Table 3. Metabolic Syndrome according to General Characteristics and Meal Regularity

\begin{tabular}{|c|c|c|c|c|}
\hline \multirow{2}{*}{ Variable } & \multirow{2}{*}{ Division } & \multicolumn{3}{|c|}{ Metabolic syndrome } \\
\hline & & Normal & Abnormal & t or $F(p)$ \\
\hline \multirow[t]{2}{*}{ Sex } & Male & $120(77.8)$ & $34(22.2)$ & $2.520(0.116)$ \\
\hline & Female & $98(85.2)$ & $22(14.8)$ & \\
\hline \multirow[t]{2}{*}{ Age } & Young adult & $113(87.6)$ & $15(12.4)$ & $6.652(0.012)$ \\
\hline & Middle-aged & $105(71.8)$ & $41(28.2)$ & \\
\hline \multirow[t]{2}{*}{ Education } & $\leq$ High school & $128(80.3)$ & $33(19.7)$ & $0.015(0.904)$ \\
\hline & $\geq$ College & $90(80.9)$ & $23(19.1)$ & \\
\hline \multirow[t]{4}{*}{ Income } & Low & $73(80.1)$ & $18(19.9)$ & $0.224(0.861)$ \\
\hline & Middle-low & $61(83.4)$ & $11(16.6)$ & \\
\hline & Middle-high & $39(77.2)$ & $16(22.8)$ & \\
\hline & High & $45(81.6)$ & $11(18.4)$ & \\
\hline \multirow[t]{2}{*}{ Smoking } & Non-smoker & $96(81.4)$ & $23(18.6)$ & $0.063(0.803)$ \\
\hline & Current smoker & $122(80.1)$ & $33(19.9)$ & \\
\hline \multirow[t]{2}{*}{ Alcohol intake } & $<1$ time/month & $25(84.6)$ & $7(15.4)$ & $0.373(0.543)$ \\
\hline & $\geq 1$ time $/$ month & $193(80.2)$ & $49(19.8)$ & \\
\hline \multirow[t]{3}{*}{ Meal regularity/day } & $\leq$ One time regularity & $40(79.6)$ & $9(20.4)$ & $0.129(0.869)$ \\
\hline & Two times regularity & $112(79.9)$ & $32(20.1)$ & \\
\hline & Three times regularity & $66(83.0)$ & $15(17.0)$ & \\
\hline
\end{tabular}

Values are presented as unweighted count (weighted \%).

F: Rao-Scott test. 
Table 4. Metabolic Syndrome according to Oral Health

\begin{tabular}{llrrrr}
\hline \multirow{2}{*}{ Variable } & Division & \multirow{2}{*}{ Total } & \multicolumn{3}{c}{ Metabolic syndrome } \\
\cline { 5 - 6 } & & & Normal & Abnormal & t or F(p) \\
\hline Perceived oral health & Good & $30(10.5)$ & $22(78.9)$ & $8(21.1)$ & $0.228(0.792)$ \\
& Moderate & $124(46.8)$ & $102(82.5)$ & $22(17.5)$ & \\
Speech problem & Poor & $120(42.7)$ & $94(79.0)$ & $26(21.0)$ & $11.731(0.002)$ \\
& Yes & $9(2.5)$ & $2(14.6)$ & $7(85.4)$ & \\
Chewing difficulty & Neutral & $29(10.7)$ & $12(43.0)$ & $17(57.0)$ & \\
& No & $236(86.8)$ & $42(16.6)$ & $194(83.4)$ & \\
Toothache experience & Yes & $44(13.8)$ & $15(14.7)$ & $29(85.3)$ & $8.553(0.034)$ \\
& Neutral & $54(19.3)$ & $13(25.7)$ & $41(74.3)$ & \\
Frequency of toothbrushing/day & No & $176(66.9)$ & $28(33.2)$ & $148(66.8)$ & \\
& Yes & $83(28.8)$ & $63(75.8)$ & $20(24.2)$ & $1.268(0.263)$ \\
& No & $191(71.2)$ & $155(82.6)$ & $36(17.4)$ & \\
& $2 \sim 3$ & $11(3.8)$ & $7(49.6)$ & $4(50.4)$ & $2.770(0.047)$ \\
& $\geq 4$ & $219(80.8)$ & $173(81.3)$ & $46(18.7)$ & $6(15.2)$ \\
\end{tabular}

Values are presented as unweighted count (weighted \%).

F: Rao-Scott test.

significant difference in metabolic syndrome according to speech problems, chewing difficulty, and frequency of toothbrushing. In the case of no speech problem, metabolic syndrome was abnormal in $83.4 \%$, and in those with speech problems it was $85.4 \%$, which was higher than that of the non-speech problem, indicating statistical significance $(\mathrm{F}=11.731, \mathrm{p}=0.002)$. In the case of no chewing difficulty, the metabolic syndrome was abnormal $(66.8 \%)$ and in the case of chewing difficulty the metabolic syndrome was $85.3 \%$, which was higher and was thus statistically significant $(\mathrm{F}=8.553, \mathrm{p}=0.034)$. In addition, when the frequency of toothbrushing was 2 to 3 times and 4 times or more, the metabolic syndrome was abnormal by $18.7 \%$ and $15.2 \%$, respectively, and in the case of less than one frequency of toothbrushing, the metabolic syndrome was abnormal at 50.4\%, which was higher and was therefore statistically significant $(\mathrm{F}=2.770, \mathrm{p}=0.047)$.

\section{Factors affecting metabolic syndrome in single-person households}

To identify the factors affecting metabolic syndrome in single-person households, a complex sample logistic regression analysis was performed using general characteristics, meal regularity, and oral health as independent variables, as shown in Table 5. The factors influencing metabolic syndrome were age, speech problems, and frequency of toothbrushing. The risk of metabolic syndrome was significantly higher in the middle-aged group than in the young group by 0.361 times $(95 \%$ confidence interval $[\mathrm{CI}], 0.162 \sim 0.806 ; \mathrm{p}=0.014)$; and 1.161 times $(95 \% \mathrm{CI}, 0.193 \sim 6.985 ; \mathrm{p}=0.018)$ in the case of difficulty in speech problems compared to the case of no speech problem, which was significantly higher. In addition, compared to subjects with a frequency of toothbrushing more than four times a day, the risk of metabolic syndrome in those with a frequency of toothbrushing less than once a day was 5.673 times $(95 \%$ CI, 1.148 28.038; $\mathrm{p}=0.034)$ and those who had a toothbrushing frequency of 2 to 3 times the risk was 1.284 times $(95 \%$ CI, 0.422 3.911; $\mathrm{p}=0.027)$, which was significantly higher.

\section{Discussion}

While rapid changes in the population structure are causing fundamental changes in society, economy, and culture, the increase in single-person households has led to drastic changes in daily life, such as residential environment, consumption structure, and dietary habits ${ }^{21)}$. Risk factors overlap $^{22)}$, and substantial health-care assistance is necessary 
Table 5. Factors affecting Metabolic Syndrome

\begin{tabular}{|c|c|c|c|c|}
\hline Variable & Division & OR & $95 \% \mathrm{CI}$ & p-value \\
\hline \multirow[t]{2}{*}{ Sex } & Female & 1.0 & & \\
\hline & Male & 1.645 & $0.879 \sim 3.078$ & 0.118 \\
\hline \multirow[t]{2}{*}{ Age } & Young adult & 1.0 & & \\
\hline & Middle-aged & 0.361 & $0.162 \sim 0.806$ & 0.014 \\
\hline \multirow[t]{2}{*}{ Education } & $\leq$ High school & 1.041 & $0.541 \sim 2.004$ & 0.904 \\
\hline & $\geq$ College & 1.0 & & \\
\hline \multirow[t]{4}{*}{ Income } & Low & 1.302 & $0.421 \sim 4.024$ & 0.829 \\
\hline & Middle-low & 0.881 & $0.286 \sim 2.719$ & 0.700 \\
\hline & Middle-high & 1.101 & $0.455 \sim 2.660$ & 0.630 \\
\hline & High & 1.0 & & \\
\hline \multirow[t]{2}{*}{ Smoking } & Non-smoker & 1.0 & & \\
\hline & Current smoker & 1.084 & $0.573 \sim 2.049$ & 0.803 \\
\hline \multirow[t]{2}{*}{ Alcohol intake } & $<1$ time/month & 1.0 & & \\
\hline & $\geq 1$ time/month & 1.350 & $0.507 \sim 3.599$ & 0.544 \\
\hline \multirow[t]{3}{*}{ Meal regularity/day } & $\leq$ One time regularity & 1.020 & $0.377 \sim 2.761$ & 0.691 \\
\hline & Two times regularity & 1.254 & $0.406 \sim 3.875$ & 0.588 \\
\hline & Three times regularity & 1.0 & & \\
\hline \multirow[t]{3}{*}{ Perceived oral health } & Good & 1.0 & & \\
\hline & Moderate & 0.793 & $0.280 \sim 2.244$ & 0.988 \\
\hline & Poor & 0.992 & $0.353 \sim 2.792$ & 0.554 \\
\hline \multirow[t]{3}{*}{ Speech problem } & No & 1.0 & & \\
\hline & Neutral & 0.264 & $0.116 \sim 0.599$ & 0.493 \\
\hline & Yes & 1.161 & $0.193 \sim 6.985$ & 0.018 \\
\hline \multirow[t]{3}{*}{ Chewing difficulty } & No & 1.0 & & \\
\hline & Neutral & 0.347 & $0.144 \sim 0.833$ & 0.869 \\
\hline & Yes & 0.497 & $0.213 \sim 1.160$ & 0.095 \\
\hline \multirow[t]{2}{*}{ Toothache experience } & No & 1.0 & & \\
\hline & Yes & 1.514 & $0.726 \sim 3.157$ & 0.265 \\
\hline \multirow[t]{3}{*}{ Frequency of toothbrushing/day } & $\leq 1$ & 5.673 & $1.148 \sim 28.038$ & 0.034 \\
\hline & $2 \sim 3$ & 1.284 & $0.422 \sim 3.911$ & 0.027 \\
\hline & $\geq 4$ & 1.0 & & \\
\hline
\end{tabular}

CI: confidence interval, OR: odds ratio.

By complex sample logistic regression analysis.

due to the poor living conditions of single-person households, which have relatively poor lifestyles compared to multi-person households. Thus, this study was conducted to examine the oral health in single-person households with metabolic syndrome, which has been linked to various lifestyle factors, including dietary habits ${ }^{23)}$ and to determine their effect on the risk of developing metabolic syndrome.

According to a study of meal regularity in single Korean households, there were statistically significant differences between age and alcohol intake, with young people in irregular or regular meal groups outnumbering middle-aged people, and middle-aged people outnumbering young people in regular three meal groups. Middle-aged people tend to eat three meals regularly due to their health concerns, on the other hand, income and employment instability are high and economic activities are often required to maintain a livelihood, affecting the dietary habit of young people ${ }^{24)}$, which can be attributed to the prevalence of one meal. In the case of single-person households, $90.6 \%$ of those who skipped meals or drink more than once a month and consumed instant food ${ }^{25)}$ are found to drink because they do not have the time or are lazy and there was a significant difference in the meal regularity. In addition, those who eat one meal a day and those who eat three meals a day, both indicated a higher 
rate of metabolic syndrome when they drank more than once a month. Thus, the living conditions of single-person households proved to be highly unstable and the need for health care is emphasized. Therefore, it is necessary to improve health-related lifestyles and strengthen policy support for psychological health.

While considering oral health according to the general characteristics of single-person households and meal regularity, in the case of women, more respondents answered that their perceived oral health was poorer than good, and in the case of male, more subjects answered it was moderate than poor. Although female perceived their oral health more negatively than male, as the selfevaluation method of oral health is subjective, it is thought that the response may vary depending on the level of interest in oral health, and objective indicators for evaluating oral health should be prepared in the future.

Middle-aged individuals had higher rate speech problems (4.9\%) and chewing difficulty (23.8\%) than the younger individuals, and the older they were, the more difficult it was to speak and chew. According to $\mathrm{Kim}^{26)}$, the older the age, the more uncomfortable it was to chew and pronounce and thus the prevalence was higher in the middle-aged compared to the younger group, which is consistent with the findings of this study. Mastication, pronunciation, and swallowing are important functions of the oral cavity. The tongue, which plays an important role in pronunciation and assists in mastication, plays a key role in swallowing and swallowing food ${ }^{27)}$. Therefore, it is necessary to check the functions of mastication, pronunciation, and tongue simultaneously. However, as the relevant factors were omitted from the data of the KNHANES, it is necessary to supplement and investigate these factors.

If such oral functions become problematic, it is another cause of deteriorating health, as well as a major cause of deteriorating oral health-related quality of life, therefore multidimensional support such as social welfare support should be provided to maintain oral health even as people age. In addition, the lower the educational level, the higher was the chewing difficulty. This is in line with research by Kang and $\mathrm{Yu}^{28)}$ who studied metabolic syndrome and oral disease, and found that the lower the educational level, the higher the periodontitis and the lower the educational level, the higher the missing value. In addition, the study by Hawg et al. ${ }^{29)}$ proved that the lower the education level, the more chewing difficulty was, which is consistent with the results of this study. In addition, when examining meal regularity and oral health, speech problems and chewing difficulty were higher in the subjects who ate three meals a day than those who ate irregularly or regularly. This is consistent with the results of the study, which showed that middle-aged adults had more three meals a day than the young, and the results of this study also established that speaking and chewing were more difficult as the age increased. The oral cavity is the first gateway for food intake and is part of the digestive system ${ }^{30}$. If oral health cannot be maintained with increasing age and teeth are lost due to oral disease, chewing ability may be reduced, which may eventually lead to an imbalance in nutritional supply. In addition, it can lead to sunken lips and cheeks, loss of occlusal support due to a decrease in vertical height, and wrinkles, which can change facial expressions and affect pronunciation, leading to speech problems ${ }^{31}$. Therefore, to maintain a healthy life, a systematic strategy is required to prevent oral diseases, which in turn can be resolved through regular oral care. Thus, improving the quality of life, and promoting and maintaining oral health.

According to the general characteristics of single-person households and meal regularity, there were 218 normal people and 56 people with metabolic syndrome, 34 male $(22.2 \%)$ and 22 female (14.8\%) with metabolic syndrome, which was higher in male than in women. The study of Song et al. ${ }^{9)}$ using the 7 th KNHANES was similar to this study with $23.7 \%$ male and $13.4 \%$ female with metabolic syndrome. and In a study by Kim et al. ${ }^{32)}$ using the KNHANES in the 2nd year of the 6th period (2014) and the 1 st year of the 7 th period (2016), 30.3\% male and $18.3 \%$ female has metabolic syndrome, however, the differences between male and female were similar. It can be considered that the prevalence rate was low due to the difference in the samples of the KNHANES data. Compared to multi households, single-person households have a relatively low healthy eating behavior index and a high rate of accompanying metabolic syndrome due to poor lifestyle ${ }^{33)}$. Research is needed to reduce the risk of 
metabolic syndrome by subdividing various lifestyles and meal regularity.

Abnormal metabolic syndrome was higher in the middle-aged group than in the young group. This was almost the same as the result of Kwon and Lee ${ }^{34)}$, who studied metabolic syndrome-related factors and environmental factors in Korean adults, with the highest prevalence among the middle-aged, who were between 45 and 54 years of age, than the young. It is thought that the high prevalence in the elderly is the result of the characteristics of the metabolic syndrome rather than the influence of social and environmental factors. Detailed and specialized research is needed in the future by classifying them by age group. Meanwhile, in this study, smoking and drinking did not have a significant effect on metabolic syndrome, which was consistent with the study results of $\mathrm{Kim}^{26)}$ and An and Son ${ }^{35)}$. However, in a study by Kwon and Lee ${ }^{34)}$, these disparities were attributed to the fact that the characteristics of each factor for smoking and drinking were not considered. However, as smoking is reported to increase the risk of metabolic syndrome ${ }^{26)}$, even if it does not cause immediate health problems, intervention through correction of health behavior is necessary as a long-term preventive aspect.

Metabolic syndrome due to oral health was significantly higher in cases where there were speech problems, chewing difficulty, and less than one frequency of toothbrushing per day. If the oral functional problems, which causes chewing difficulty, leads to a problem of digestive function, then the intake of food is restricted, sufficient intake of nutrients cannot be achieved, which will act as a negative factor for health. Therefore, if chewing and speaking, which are important functions of the oral cavity, become difficult, it will be necessary to study whether it acts as a risk factor for metabolic syndrome. To add a comprehensive oral function, it is necessary to discuss policy methods for oral health and health promotion. In addition, a study by $\mathrm{Ku}$ and $\mathrm{Kim}^{12)}$ showed that the fewer times a person brushes in a day, the higher the metabolic syndrome and it is in the same vein as a study that reported a high risk of periodontal disease in the presence of metabolic syndrome ${ }^{14)}$. In addition, another study reported that the inflammatory state caused by periodontal disease was related to metabolic syndrome ${ }^{13)}$. These results support a study that reported that periodontal condition deterioration and periodontal disease risk $^{36)}$, and tooth loss ${ }^{37)}$ were high among the components of metabolic syndrome in the hypertensive, diabetic, and low HDL cholesterol groups. In other words, difficulty in chewing and speaking are usually caused by poor oral health, so there is a possibility that tooth loss and weakened support layer may have had an effect ${ }^{38)}$. Toothbrushing can lower the overall dental plaque index in the oral cavity and increase resistance to infection from inflammatory diseases. In addition, by improving the periodontal condition and reducing the prevalence of periodontal disease, thus reducing the risk of tooth loss, the oral health condition is improved, thereby solving the problem of chewing difficulty and speech. Furthermore, it is thought that it may affect not only oral health but also chronic diseases related to metabolic syndrome.

Therefore, for the management of risk factors of metabolic syndrome, regular and professional oral hygiene care should be recommended to reduce the incidence of oral diseases. As part of the national policy, it is necessary to develop and disseminate continuous and systematic programs such as preventive treatment education and specialized dental plaque management for the prevention of oral diseases.

As a result of complex sample logistic regression analysis to identify factors affecting metabolic syndrome in single-person households, metabolic syndrome was 0.361 times higher in the middle-aged group than in the youth group, 1.161 times higher in the case of difficulty in speech problems than in the case of no speech problems. In addition, compared to the frequency of toothbrushing more than four times a day, it was 5.673 times higher than in the case of brushing less than once a day, and 1.284 times higher in the case of 2 to 3 times. In particular, the frequency of toothbrushing per day was found to be highly related to metabolic syndrome. A study by $\mathrm{Kim}^{26}$ in single-person households found that older people are more affected by metabolic syndrome and have a relatively higher proportion of regular meals, but as a result of adverse eating habits or lifestyle influences on the occurrence of metabolic syndrome and in relation to dietary 
habits, it is thought that it is necessary to specifically confirm the interval between meal times or the metabolically unfavorable meal pattern. The older the person, the higher the percentage of regular meals, however, it is thought that specific checks on eating time intervals and metabolic patterns are essential if poor eating or lifestyle influences metabolic syndrome.

Oral health is a major component of overall health and affects the quality of life. Therefore, it is necessary to discuss concrete practical methods to reach a healthy old age and improve the quality of life. In this study, metabolic syndrome was found to be highly related to the frequency of toothbrushing, which is essential for oral health, confirming that there is a close relationship between metabolic syndrome and oral health. Less frequent brushing causes oral diseases, which reduce oral functions such as mastication and pronunciation, which leads to poor oral health. When the amount of activity is reduced, it leads to poor overall health results.

As a result of the above, the health risks faced by single-person households in Korea are corrected through the correction of lifestyle and oral health behaviors, and active intervention measures such as support and publicity at the local or national level should be prepared so that a customized care plan for single-person households can be prevented, and programs that can be applied can be implemented.

As a limitation of this study, the KNHANES data used in this study did not specifically identify the health behavior or oral health behavior of each person in a singleperson household using a cross-sectional survey. Therefore, in future studies, the implementation of a longitudinal study requires detailed association with metabolic syndrome, along with clinical data related to various dietary, lifestyle, oral, and systemic health. Nevertheless, this study aims to use the most recent data to identify the risk factors of metabolic syndrome in single Korean households that can be viewed as a universal social phenomenon through big data analysis.

\section{Notes}

\section{Conflict of interest}

No potential conflict of interest relevant to this article was reported.

\section{Ethical approval}

This study was approved by the Research Ethics Review Committee of the Korea Centers for Disease Control and Prevention (2018-01-03-C-A) and the exemption approval of the Research Ethics Review Committee of Howon University (IRB No: 1041585-202105-HR-003-01).

\section{Author contributions}

Conceptualization: Hye-Won Cheon. Data acquisition: Jin-Ah Jung. Formal analysis: Jin-Ah Jung. Funding: Hye-Won Cheon. Supervision: Jin-Ah Jung. Writingoriginal draft: Jin-Ah Jung, Hye-Won Cheon, and On-Ju Ju. Writing-review \& editing: Jin-Ah Jung, Hye-Won Cheon, and On-Ju Ju.

\section{ORCID}

Jin-Ah Jung, https://orcid.org/0000-0002-4127-9429

Hye-Won Cheon, https://orcid.org/0000-0003-4205-0199

On-Ju Ju, https://orcid.org/0000-0003-3175-2478

\section{Acknowledgements}

This research was supported by funds of Howon University.

\section{References}

1. Song SY, Jeong YH: Association between eating alone and metabolic syndrome: a structural equation modeling approach. J Korean Diet Assoc 25: 142-155, 2019. https://doi.org/10.14373/JKDA.2019.25.2.142

2. Statistics Korea: 「Single-person households in 2020 statistics」 press release. Retrieved 2021 Apr 24, from http://kostat. go.kr/portal/korea/kor_nw/1/1/index.board?bmode=read\&b Seq $=201 \&$ aSeq $=386517 \&$ page $\mathrm{No}=10 \&$ row Num $=10 \&$ navC ount $=10 \&$ currPg $=\&$ searchInfo $=\&$ sTarget $=$ title \&sTxt $=(2020$, December 8).

3. Ko GY: Single household, it also changes consumption 
landscapes. Retrieved 2021 Apr 24, from http://www.lgeri. com/report/view.do?idx=18389(2014, January 7)

4. Stone NJ, Saxon D: Approach to treatment of the patient with metabolic syndrome: lifestyle therapy. Am J Cardiol 96(4A): 15E-21E, 2005.

https://doi.org/10.1016/j.amjcard.2005.05.010

5. Wilson PW, D'Agostino RB, Parise H, Sullivan L, Meigs JB: Metabolic syndrome as a precursor of cardiovascular disease and type 2 diabetes mellitus. Circulation 112: 3066-3072, 2005.

https://doi.org/10.1161/CIRCULATIONAHA.105.539528

6. Kim SH: Effects of nutrient intake on oral health and chewing difficulty by age group. J Korea Acad-Ind Cooper Soc 19: 202-209, 2018. https://doi.org/10.5762/KAIS.2018.19.2.202

7. Lee YS, Lee MY, Lee SY: The risk of metabolic syndrome by dietary patterns of middle-aged adults in Gyeonggi province. Korean J Community Nutr 19: 527-536, 2014. https://doi.org/10.5720/kjen.2014.19.6.527

8. Yeo R, Yoon SR, Kim OY: The association between food group consumption patterns and early metabolic syndrome risk in non-diabetic healthy people. Clin Nutr Res 6: 172-182, 2017. https://doi.org/10.7762/cnr.2017.6.3.172

9. Song JY, Choi MO, Kim OY: Relationship between meal regularity and the metabolic syndrome among Korean single-person household adults under 60 years of age: based on the Seventh Korea National Health and Nutrition Examination Survey (2016 2018). J Korean Diet Assoc 27: 1-14, 2021. https://doi.org/10.14373/JKDA.2021.27.1.1

10. Nazir MA: Prevalence of periodontal disease, its association with systemic diseases and prevention. Int J Health Sci 11: 72-80, 2017.

11. Seong MG, Kwun HS, Moon SR, Ryu HG: Evaluation of the effect of operation of toothbrushing room in between two elementary schools. J Dent Hyg Sci 15: 24-31, 2015.

12. Ku IY, Kim HG: The relationship between workers health behaviorals, oral health behaviorals and metabolic syndrome risk factors periodontal disease status. J Korean Soc Dent Hyg 12: 597-609, 2012. https://doi.org/10.13065/jksdh.2012.12.3.597

13. Kushiyama M, Shimazaki Y, Yamashita Y: Relationship between metabolic syndrome and periodontal disease in Japanese adults. J Periodontol 80: 1610-1615, 2009. https://doi.org/10.1902/jop.2009.090218

14. Nibali L, D'Aiuto F, Griffiths G, Patel K, Suvan J, Tonetti MS: Severe periodontitis is associated with systemic inflammation and a dysmetabolic status: a case-control study. J Clin Periodontol 34: 931-937, 2007. https://doi.org/10.1111/j.1600-051X.2007.01133.x

15. Lee ES, Kim KM, Kim HJ: Status of oral health in relation to the acknowledgement of oral health trouble and oral health habits in recipients of dental screening in hospital. Korean J Health Serv Manag 10: 121-131, 2016. https://doi.org/10.12811/kshsm.2016.10.2.121

16. Hong MH: Relationship between oral health behavior, chronic disease and periodontal disease in middle and older adults according to gender. J Korea Acad-Ind Cooper Soc 19: 403-410, 2018.

https://doi.org/10.5762/KAIS.2018.19.11.403

17. Kim YH Lee JH: The relationship between oral health behavior, smoking, and periodontal diseases in Korea middle-aged mee: based on data from the Korea National Health and Nutrition Examination Survey, 2013-2015. J Korean Acad Oral Health 41: 36-42, 2017. https://doi.org/10.11149/jkaoh.2017.41.1.36

18. Lee JH: The relationship between metabolic syndrome components and the number of remaining teeth in Korean adults. J Korean Acad Oral Health 44: 130-137, 2020. https://doi.org/10.11149/jkaoh.2020.44.3.130

19. Lim MH: Effects of oral health knowledge, attitude, and behavior on oral health impact profile of metabolic syndrome patients. J Korean Soc Dent Hyg 18: 1079-1090, 2018. https://doi.org/10.13065/jksdh.20180093

20. Ministry of Health and Welfare; Korea Disease Control and Prevention Agency: The eight Korea National Health and Nutrition Examination Survey (KNHANES VIII-1), 2019. Retrieved 2021 May 15, from http://knhanes.kdca.go.kr/ knhanes/sub03/sub03_02M05.do(2020, March 21).

21. Gang EN, Lee MH: Single-person households in South Korea and their policy implications. Health Welf Policy Forum 234: 47-56, 2016.

22. Lee JY, Choi SK, Seo JS: Evaluation of the nutrition status and metabolic syndrome prevalence of the members according to the number of household members based on the 
Korea National Health and Nutrition Examination Survey (2013-2014). Korean J Community Nutr 24: 232-244, 2019. https://doi.org/10.5720/kjen.2019.24.3.232

23. Kim DE, Hong SH, Kim JM: The relations between diabetic dietary compliance, dietary intake, and physical activity and the prevalence of metabolic syndrome (MS) in type 2 diabetic patients. Korean J Community Nutr 20: 351-361, 2015. https://doi.org/10.5720/kjen.2015.20.5.351

24. Lee YB: One-person households and their policy implications. Health Welf Policy Forum 252: 64-77, 2017.

25. Heo YK, Shim KH: Dietary attitude of single households in metropolitan areas. Korean J Food Nutr 29: 735-745, 2016. https://doi.org/10.9799/ksfan.2016.29.5.735

26. Kim AR: Effect of health behaviors, dietary habits, and psychological health on metabolic syndrome in one-person households among Korean young adults. J Digit Converg 16: 493-509, 2018.

https://doi.org/10.14400/JDC.2018.16.7.493

27. Youmans SR, Youmans GL, Stierwalt JA: Differences in tongue strength across age and gender: is there a diminished strength reserve? Dysphagia 24: 57-65, 2009. https://doi.org/10.1007/s00455-008-9171-2

28. Kang HJ, Yu BC: Relationship between metabolic syndrome and oral diseases in the middle aged and elderly people. J Korean Soc Dent Hyg 15: 947-961, 2015. https://doi.org/10.13065/jksdh.2015.15.06.947

29. Hwang SH, Han SS, Yoo WK: The effects of chewing difficulty on the prevalence of osteoarthritis in adults aged 50 years and older. J Dent Hyg Sci 15: 145-152, 2015. https://doi.org/10.17135/jdhs.2015.15.2.145

30. Lee ES, Do KY: Association between chewing problems and depression in Korean adults. J Korean Soc Dent Hyg 19:
753-763, 2019.

https://doi.org/10.13065/jksdh.20190064

31. Yeo IS, Ko MH, Kwon HM, et al.: Prosthodontics. 5th ed. Komoonsa, Seoul, pp.63-64, 2019.

32. Kim CJ, Park JB, Kim BT: Lifestyle Characteristics, metabolic syndrome risk factors and risk of cardiovascular disease among workers in Kyeongki-do. Korean J Occup Health Nurs 17: 230-238, 2008.

33. Jung CH, Park JS, Lee WY, Kim SW: Effects of smoking, alcohol, exercise, level of education, and family history on the metabolic syndrome in Korean adults. Korean J Med 63: 649-659, 2002.

34. Kwon LS, Lee SH: Environmental factors related factors of metabolic syndrome of Korean adults- focused on the Fourth Term Korea National Health \& Nutrition Examination Survey -. J Korean Living Env Syst 19: 676-688, 2012.

35. An BM, Son JH: Analysis of metabolic syndrome in Korean adult one-person households. J Korean Public Health Nurs 32: 30-43, 2018. https://doi.org/10.5932/JKPHN.2018.32.1.30

36. Kim SY, Jang HG: Influence of metabolic on periodontal disease in Korean adults. J Korean Soc Dent Hyg 15: 399-410, 2015. https://doi.org/10.13065/jksdh.2015.15.03.399

37. Kang HJ: A study on periodontal disease and tooth loss in metabolic syndrome patient. J Dent Hyg Sci 15: 445-456, 2015. https://doi.org/10.17135/jdhs.2015.15.4.445

38. Furuta M, Yamashita $Y$ : Oral health and swallowing problems. Curr Phys Med Rehabil Rep 1: 216-222, 2013. https://doi.org/10.1007/s40141-013-0026-x 